\title{
InSe ve InSe:Sn Yarıiletkenlerinde Farklı Tavlama Sıcaklıkları ve Süreleri için Lineer Soğurma Katsayılarının Belirlenmesi
}

\section{Determination of Linear Attenuation Coefficients for Different Annealing Temperatures and} Duration in InSe and InSe:Sn Semiconductors

\author{
Burcu AKÇA*1,a, Salih Zeki ERZENEOĞLU ${ }^{2, b}$ \\ ${ }^{1}$ Ardahan Üniversitesi, Mühendislik Fakültesi, Bilgisayar Mühendisliği Bölümü, 75000, Ardahan \\ ${ }^{2}$ Atatürk Üniversitesi, Fen Fakültesi, Fizik Bölümü, 25400, Erzurum
}

• Geliş tarihi / Received: 10.04.2018

• Düzeltilerek geliş tarihi / Received in revised form: 07.05 .2018

- Kabul tarihi / Accepted: 11.05 .2018

Öz

Bu çalışmada Bridgman/Stockbarger metodu ile büyütülmüş InSe ve InSe:Sn yariiletken kristallerinin farklı tavlama sıcaklıkları ve zamanları için lineer soğurma katsayıları incelenmiştir. Yarıiletkenlerden geçirilen ${ }^{241}$ Am'in gamma 1şınları yüksek çözünürlüklü $\mathrm{Si}(\mathrm{Li})$ detektör tarafından detekte edilmiştir ve Enerji ayırımlı X-1şını Floresan Spektrometresi (EDXRFS) kullanılmıştır. InSe ve InSe:Sn yarıiletken kristallerinin lineer soğurma katsayılarının, tavlama süresi ve sıcaklığının artışıyla genelde arttığı gözlenmiştir.

Anahtar kelimeler: Bridgman/Stockbarger, EDXRFS, Lineer soğurma katsayısı, InSe

\begin{abstract}
In this study have examined linear attenuation coefficients of InSe and InSe:Sn semiconductor crystals have been grown by using Bridgman/Stockbarger for different annealing temperature and time. Gamma rays of ${ }^{241}$ Am passed through semiconductors have been detected by a high-resolution Si(Li) detector and by using energy dispersive X-ray fluorescence spectrometer (EDXRFS). It has been observed that the linear absorption coefficients of InSe and InSe: Sn semiconductor crystals generally increase with the increase of annealing time and temperature.
\end{abstract}

Keywords: Bridgman/Stockbarger, EDXRFS, Linear attenuation coefficient, InSe

\footnotetext{
*a Burcu AKÇA; burcuakca@ardahan.edu.tr; Tel: (0478) 2117512 (dahili: 2221); orcid.org/0000-0003-2399-5971

${ }^{\mathrm{b}}$ orcid.org/0000-0002-0890-6099
} 


\section{Giriş}

InSe ikili bileşikleri veya kristalleri tabakalı yapıya sahip olup tabakalı yapılar oldukça fazla anizotropik özelliklere sahiptir. II-VI, II-IV veya III-V grubu yariiletkenlerdeki gibi 3 boyutlu bağlanma yerine bu kristallerde moleküler bağlanma iki boyutta I. mertebeden iyonik veya kovalent bağlardır. Bu bağlanma şekli, tabakalı yarriletkenlerin eşsiz özelliklerinin ortaya çıkma sebebidir ve bu yarıiletkenler belirgin bir şekilde diğer klasik yarıiletkenlerin band yapısı, titreşim spektrumu, optik özellikleri ve mekanik özelliklerinden tamamen farklıdırlar (Segura vd., 1983). İndiyum III-A grubu elementi olup, atom numaras1 49 , kütle numarası ise 114,818 ' dir. VI-A grubu elementi olan selenyumun ise atom numaras1 34, kütle numaras1 ise 78.950'dir. Yariiletkenlerin III-VI tabakalı ailesinin en karakteristik özelliği katmanların varlı̆̆ıdır. $\mathrm{Bu}$ aile $\mathrm{A}^{\mathrm{III}} \mathrm{B}^{\mathrm{VI}}$ tipi bileşiklerin tek kristali olarak bilinmektedir (Mooser, 1976). InSe kristali Se-InIn-Se yapısında kristalleşir (Olguin vd., 2003). Atomlar birbirlerine kovalent veya iyonik bağla bağlanmışlardır ve her bir tabaka arasında Vander Waals bağı vardır. InSe bileşiğinde indiyum düzlemindeki her bir atom, bitişiğindeki selenyum atomik düzleminde yer alan üç selenyum atomuna ve diğer tarafta ise bir indiyum atomuna yakın komşudur. Selenyum atomları arasındaki mesafe, indiyum atomları arasındaki mesafeden daha fazladır ve indiyum ve selenyum atomları arasındaki bölgede bir asimetri söz konusudur. Birbiri üzerine gelen iki boyutlu atomik düzlemler aras1 mesafe, oluşan politipin örgüsünü belirler (Choi ve Peter 2003). İkili yariiletken bileşikler, görünür ve kızılötesi 1şık yayan diyotlar, kızılötesi detektörler, optik parametrik osilatörler, doğrusal olmayan optikler, güneş pilleri, optik frekans dönüştürücü, ikinci dereceden harmonik üretim cihazları ve birçok elektro-optik cihazlar gibi pratik uygulamalardan dolayı teknolojik olarak ilgi çekicidirler (Pellicer-Pores vd.,. 2002). Yarriletken bileşikler ince film üretilmesi için substrat olarak kullanılmalarına rağmen, güneş pillerinin fabrikasyonu için son y1llarda daha dikkat çekici hale gelmişlerdir. Son zamanlarda ise indiyum selen ince filmlerin büyütülmesi, indiyum selenin optoelektronik ve fotovoltaik uygulamalar için sahip olduğu potansiyelden dolayı fazlaca ilgi çeken bir çalışma konusu haline gelmiştir. Yariiletken kristaller ile ilgili literatür de verilen birkaç çalışma: İçelli vd. (2005)'de Stockbarger metodu kullanılarak büyütülmüş ntipi InSe ve Gd, Ho, Er elementleri ile katkılandırılmış InSe kristallerinin kütle azaltma katsayılarını, 15.746-40.930 keV enerji aralığında
$\mathrm{Si}(\mathrm{Li})$ detektör ve EDXRF sistemi kullanarak ölçmüşlerdir. Erzeneoğlu vd. (2006)'da Bridgman-Stocbarger metodu kullanılarak elde edilmiş InSe ve farklı konsantrasyonlarda Holmiyum katkılanmış InSe kristallerinin 15.746$40.930 \mathrm{keV}$ enerji aralığındaki kütle soğurma katsayılarını ölçmüşlerdir. Abdinov vd., (2012)' de n-tipi InSe kristallinin fotoiletkenliğine dış elektrik alanın etkisini çalışmışlardır. Darwish vd. (2013)'de Hegzegonal sistem ile InSe tozlarının polikristal olduklarını tespit etmiş̧lerdir. Ayrıca X1şını kırınımlı taramalı elektron mikroskobu kullanarak InSe filmlerin doğal nano yapıya sahip olduklarını göstermişlerdir. Akça vd. (2015)'de bazı katkılı ve katkısız yarıiletken kristallerin farklı tavlama sıcaklığı ve sürelerindeki gama transmisyon faktörlerini ölçmüşlerdir.

$\mathrm{Bu}$ çalışmada Bridgman/Stockbarger metodu ile büyütülmüş InSe ve InSe:Sn yariiletken kristallerinin farklı tavlama sicaklıkları ve zamanları için lineer soğurma katsayıları dar-1şın geometrisi kullanılarak ölçülmüştür. Yariiletken malzemenin $\gamma$-1şını geçirgenliği hakkında bilgi veren lineer soğurma katsayılarının, kristalin kusur ve düzensizliğini minimuma indirmek için kullanılan tavlamanın, sıcaklık ve süresinin lineer soğurma katsayıları üzerindeki değişimi incelenmiştir. Çalışmamızdaki amaç, ihtiyaca göre kullanılacak numuneler de hangi amaç güdülüyorsa ona göre tavlama süresi ve tavlama sıcaklığı belirlenebileceğidir, öyleki amaç daha soğurucu bir numuneyse lineer soğurma katsayısını arttıracak yönde, daha geçirgen bir numuneyse de lineer soğurma katsayısını azaltacak yönde bir işlem yapılabileceğidir.

\section{Materyal ve Metot}

\subsection{Deney Geometrisi}

Çalışmada öncelikle kaynak-numune-detektör sistemi oluşturulmuştur. Sistemde dar-1şın geometrisi oluşturmak için yeterli foton akısını elde edebilecek şekilde, farklı delik çaplarına sahip, silindirik kolimatörler kullanılmıştır. Havadan saçılma etkilerinin ortadan kaldırılması için, aynı deneysel şartlar altında numunesiz ölçümler alınmıştır ve bu sayımlar numuneli ölçümlerden çıkarılmışıır. Numuneli ve numunesiz sayımlar için aynı sayma zamanı kullanılmıştır. Numuneli ve numunesiz sayımlar için bir örnek spektrum Şekil 1'de verilmiştir. Çalışmamız için hazırlanan dar 1 şın geometrisi Şekil 2'de verilmiştir. 


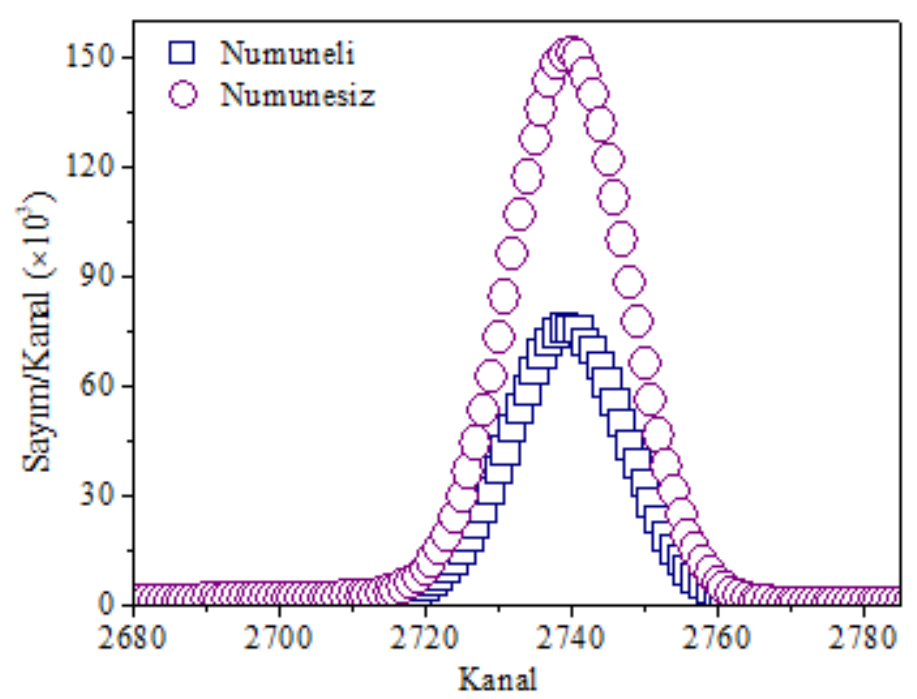

Şekil 1. Numuneli (InSe) ve numunesiz sayımlar için örnek bir spektrum

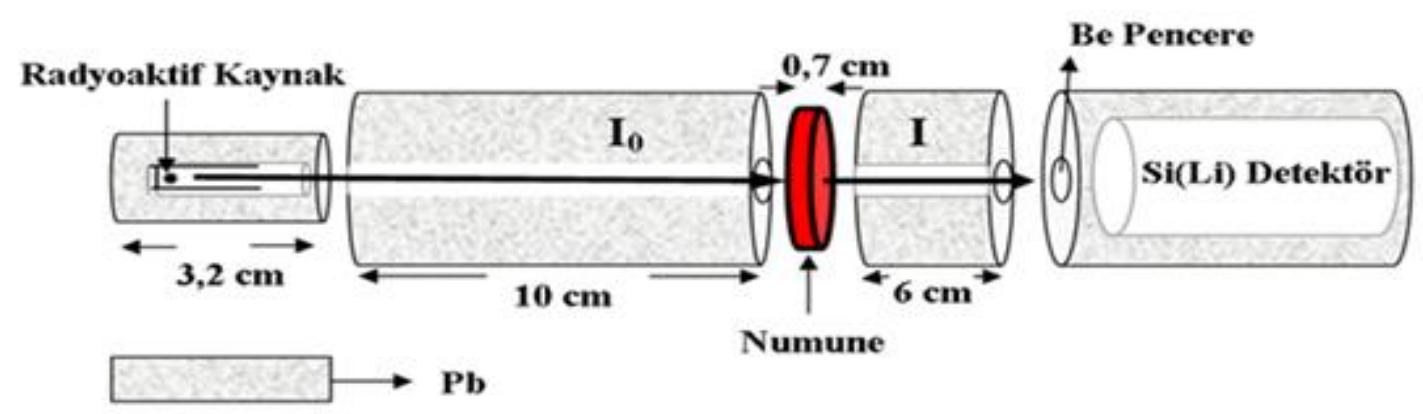

Şekil 2. Deney için hazırlanan dar-1şın geometrisi

Çalıșmamız da aktif çapı $3.91 \mathrm{~mm}$, aktif alanı 12 $\mathrm{mm}^{2}$ ve $5.9 \mathrm{keV}^{\prime}$ de FWHM'u $160 \mathrm{eV}$ olan bir $\mathrm{Si}(\mathrm{Li})$ detektör kullanılmıştır. Deney süresince sayaç kristali ve FET 30 litrelik bir sıvı azot kabına bağlı, sıvı azot sıcaklığında tutulmuştur. Detektör diş ortamdan gelebilecek yüzey kirlenmelerini önlemek için $0.025 \mathrm{~mm}$ kalınlığında bir berilyum pencereye sahiptir. Ölçü alma süresince çevresel koşulların olabildiğince değiştirilmemesine dikkat edilmiştir. Deneyde, şiddeti $100 \mathrm{mCi}$ olan $\mathrm{Am}-241$ radyoaktif kaynağının $59.5 \mathrm{keV}$ enerjili fotonları ve sayma sistemi olarak da EDXRF (Energy Dispersive XRay Fluorescence) spektrometresi kullanılmıştır. Analizör 4096 kanalda olacak şekilde, $600 \mathrm{~s}$ sayma süresinde ölçüler en az üç kez tekrarlanarak ortalamaları alınmıştır.

Çalışmamızda deneysel hataların bertaraf edilmesi ya da minimum seviyeye indirilmesi için gerekli çaba sarf edilmiştir. İdeal bir transmisyon deneyinde bütün fotonlar paralel bir şua gibi soğurucu materyale gönderilmelidir. Fakat deneysel çalışmalarda her durumda sistematik, operasyonel vb. hatalar vardır. Bu hatalar; sayma istatistiği, soğurucunun bütünselliğinin olmaması, numunelerin kirlilik içermesi ve saçılan fotonların detektöre ulaşamamasından kaynaklanmaktadır. $\mathrm{Bu}$ hatalar için ortalama değerden sapmalar yüzde olarak $\mathrm{I}_{0}$ ve $\mathrm{I}(<\% 1.3)$, numune kalınlığ $(<\% 0.7)$, numunenin kütlesi $(<\% 0.2)$, sistematik hata $(<\% 0.8)$, tavlama sıcaklığının belirlenmesinden kaynaklanan hata $(\leq \% 0.83)$ ve tavlama zamanın belirlenmesinden kaynaklanan hata $(\leq \% 1.7)$ olarak tespit edilmiştir.

\subsection{Numunelerin hazırlanmast}

InSe ve InSe:Sn (yüzde 0.01 ağırlık Sn) kristal büyütme araştırma laboratuvarımı da Bridgman/Stockbarger metodu kullanılarak Dr. Öğr. Üyesi Bekir GÜRBULAK tarafından büyütülmüştür. Stockbarger metoduyla kristal büyütme Bridgman tekniğinin geliştirilmiş şeklidir. Bridgman ve Stockbarger tekniklerinin her ikisinde de sabit bir firın söz konusudur. Bridgman tekniğinde firın içerisindeki ampul hareketlidir ve sabit firın, sabit sicaklık 
gradyentine sahiptir. Stockbarger tekniğinde ise sabit firın içerisindeki ampul hareketli olmayıp, fırın içerisindeki sıcaklık gradyenti belirli adımlarla düşürülmektedir. Bridgman tekniğinde, büyütülmek istenilen kristal, firın tüpü boyunca oluşan sicaklık gradiyenti boyunca yatay veya düşey olarak hareket ettirilebilir. Bu metotlara sirasıyla yatay Bridgman ve düşey Bridgman metotları denilmektedir. Numuneler hazırlanırken külçe yüzeyde herhangi bir çatlak veya boşluk olmamalıdır. Numunelerin doğal aynaya benzer bölünme yüzeyleri üzerinde herhangi bir temizlik ve cilalama işlemi gerçekleştirilmemelidir. Katkısız ve katkılı InSe kristali yaklaşık $10 \mathrm{~mm}$ çapında ve $60 \mathrm{~mm}$ uzunluğunda külçe olarak hazırlanmıştır. Tek kristal elde etmek için, kristal büyütme işleminden önce bu kristallere ait faz diyagramlarının bilinmesi ve incelenmesi gerekir. Faz diyagramlarının koordinatları; basınç sabit kabul edilerek sıcaklık ve kompozisyon olarak ele alınmaktadır. Yarıiletken bileşiklerden, tek kristal elde edilebilmesi için erime sıcaklığı ve bileşiğin karşılıklı çözünebilirliğinin bilinmesi gerekir. İndiyum Selenyumun erime sıcaklığı, $660 \pm 5{ }^{\circ} \mathrm{C}$ olarak belirlenmiştir. InSe yariiletkeninin erime sıcaklığının tespiti için kullanılan faz diyagramı Şekil 3’te gösterilmiştir.

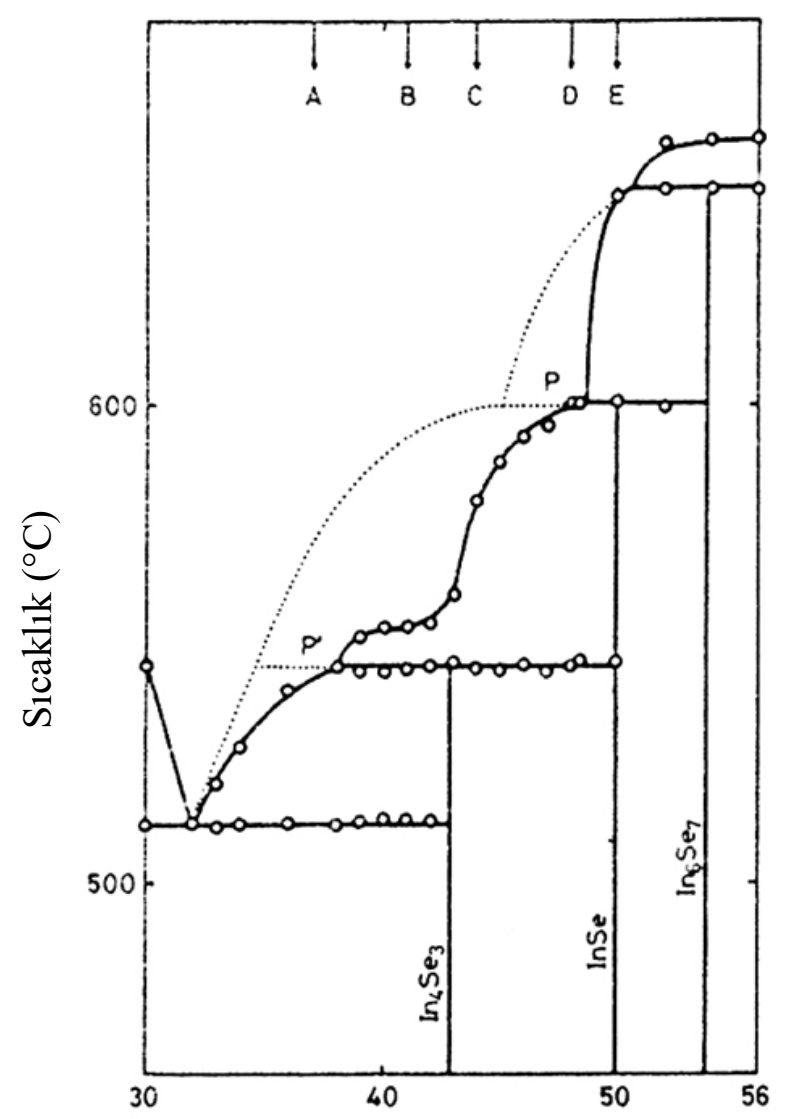

Şekil 3. InSe yarıiletken bileşiğinin faz diyagramı (Imai vd., 1981)
InSe ve InSe:Sn, 0-60 dak (dakika) zaman aralığın da, 10 dakikalık zaman artışlarıyla $50^{\circ} \mathrm{C}$ sıcaklıktan başlanarak $50^{\circ} \mathrm{C}^{\prime} l 1 \mathrm{k}$ sicaklık artışlarıyla yanma sıcaklığına gelinceye kadar tavlanmışlardır. Tavlama için kullanılan fırın 0$1200^{\circ} \mathrm{C}$ sıcaklık aralığında çalışmaktadır. InSe için yanma sicakl 1 ğ $300^{\circ} \mathrm{C}$ iken, InSe:Sn için bu sicaklık $350^{\circ} \mathrm{C}$ 'dir. InSe için $300^{\circ} \mathrm{C} \max$ tavlanabildiği sicaklıktır numune bu sicaklıktan sonra yanmıştır, InSe:Sn içinde aynı durum $350^{\circ} \mathrm{C}$ de ortaya çıkmıştır. Yariiletken kristallerimizin kalınlığ 1 ise $638 \mu \mathrm{m}$ 'dir.

\subsection{Teori}

Madde ve elektromanyetik radyasyon etkileşmesi sonucu meydana gelen soğurma ve saçılma olaylarının, daha iyi bir şekilde açıklanmasında tesir kesitleri, soğurma ve saçılma katsayıları önemli rol oynamaktadırlar. Literatürde birçok çalışmada; inşaat malzemeleri, metal alaşımlar, mineral numuneler, kemik, kas ve yă gibi biyolojik numuneler için kütle soğurma, lineer azaltma, transmisyon katsayıları için doğru ölçümler aranmıştır. İletilen ışının azaltılması ölçülerek kütle azaltma katsayıları deneysel olarak elde edilebilir. $\mathrm{Bu}$ metot Beer-Lambert eşitliği denilen bir ifadeyle tanımlanır. Radyasyonun şiddetinde meydana gelen azalma soğurucu malzemenin kalınlığı (t) ile orantılıdır.

Başlangıçtaki şiddeti $\mathrm{I}_{0}$ olan elektromanyetik radyasyonun bir soğurucu tabakasından geçtikten sonraki I şiddeti,

$\mathrm{I}=\mathrm{I}_{0} \cdot \mathrm{e}^{-\mu \mathrm{t}}$

$\mu=\frac{\ln \left(I_{0} / I\right)}{t}$

Burada $\mu\left(\mathrm{cm}^{-1}\right)$ lineer soğurma katsayısı, $\mathrm{I} / \mathrm{I}_{0}$ oranı ise transmisyon faktörü veya transmisyon katsayısı $(T)$ adını alır.

\section{Bulgular ve Tartışma}

Yariiletken malzemelerin veya kristallerin kusursuz olması mümkün değildir. Malzeme içerisinde kirlilik atomları veya örgü kusurları bulunabilir. Kirlilik atomları veya örgü kusurlarının etkisini minimuma indirmek için kristal gibi bir madde veya devre elemanı 1siya tabi tutulmaktadır. Tavlama işlemi, denilen bu işlem sonunda, yapıdaki atomik düzensizlikler 
azalır ve daha düzenli bir faz oluşur. Yariletkenlerin tavlanmas1, malzemeler üzerinde farklı etkiler oluşturmaktadır ki bu etkiler, şu şekilde sıralanabilir. Birincisi; yüksek sıcaklıklarda, yariletken maddeler katkılı karakteristiğini kaybederek, daha çok asal yariletken gibi davranmaya başlar. Çünkü asal taşıyıcı konsantrasyonu sicaklığın kuvvetli bir fonksiyonudur. İkincisi; yariiletkenlerde sicaklığa bağlı olan taşıyıcı mobilitesini etkiyen fonon veya örgü saçılması ve iyonize olmuş kirlilik saçılması olabilir. Bir yariiletken kristaldeki atomlar, mutlak sıfırın üzerindeki sıcakliklarda belirli bir termal enerjiye sahiptirler ve bu enerji nedeniyle kristal içinde örgü atomları örgü pozisyonu civarında rasgele titreşim hareketi yaparlar. Örgü titreşimleri mükemmel periyodik potansiyel fonksiyonunda bir bozulmaya sebep olur. Üçüncüsü; oda sıcaklığından daha yüksek sıcaklıklara (> 300 K) çıkıldığında asal taşıyıcı konsantrasyonu artar ve iletkenlikle birlikte elektron konsantrasyonu baskın olmaya başlar. Dördüncüsü; asal taşıyıcı konsantrasyonu ve Fermi enerji seviyesi sıcaklığın kuvvetli bir fonksiyonudur.

Sıcaklık artışıyla birlikte asal taşıyıcı konsantrasyonu artar ve Fermi enerji seviyesine yaklaşacak şekilde hareket eder. Yüksek s1caklıklarda, yariletken madde katkılı karakteristiğini kaybetmeye ve daha çok asal yarriletken gibi davranmaya başlar. Beşincisi ise; kristaldeki atomlar sicaklığın bir fonksiyonu olarak termal enerjiye sahiptirler. $\mathrm{Bu}$ termal enerji, atomların denge örgü noktası civarında rasgele titreşmesine sebep olur. $\mathrm{Bu}$ rasgele termal hareket, atomların mükemmel geometrik dizilimini bozar veya düzenli dizilmiş atomlar arasındaki mesafenin rasgele değişmesine de sebep olabilir. Bu örgü kusuru olarak adlandırılır (Neamen, 2003).

Lineer soğurma katsayılarının tavlama sıcaklığı ve tavlama süresine göre değişimlerinin deneysel değerleri; Şekil 4-10'da verilmiştir. InSe ve InSe:Sn kristallerinin lineer soğurma katsayılarının, tavlama süresinin artışıyla genelde arttığı belirlenmiştir.

Tavlama sıcaklığı dikkate alındığında, InSe kristali için 40. dakika ve $300{ }^{\circ} \mathrm{C}^{\prime}$ de; InSe:Sn kristali için ise 60 . dakika ve $350{ }^{\circ} \mathrm{C}$ 'de lineer soğurma katsayılarının maksimum değere ulaştığı belirlenmiştir. Normal şartlarda kalınlık arttıkça azalan lineer soğurma katsayısının, bu tek kristaller için kalınlık değiştirilmeksizin, belirli sıcaklık ve sürelerde tavlama yapıldığında tavlama süresi değişimiyle arttı̆̆ gözlenmiştir.

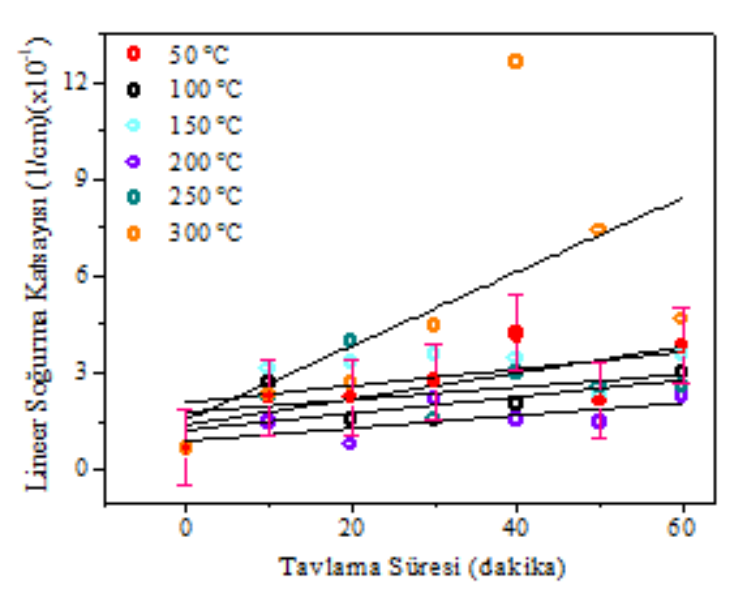

Şekil 4. InSe için tavlama süresi ile lineer soğurma katsayısı değişimi

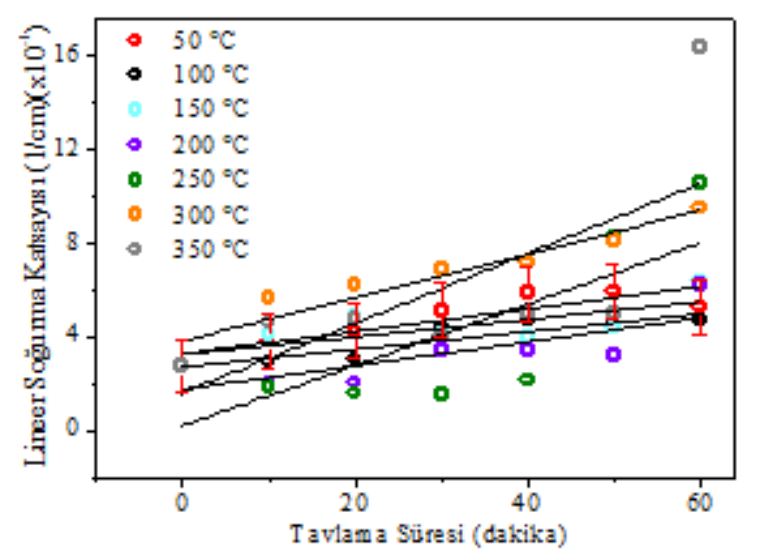

Şekil 5. InSe:Sn için tavlama süresi ile lineer soğurma katsayısı değişimi

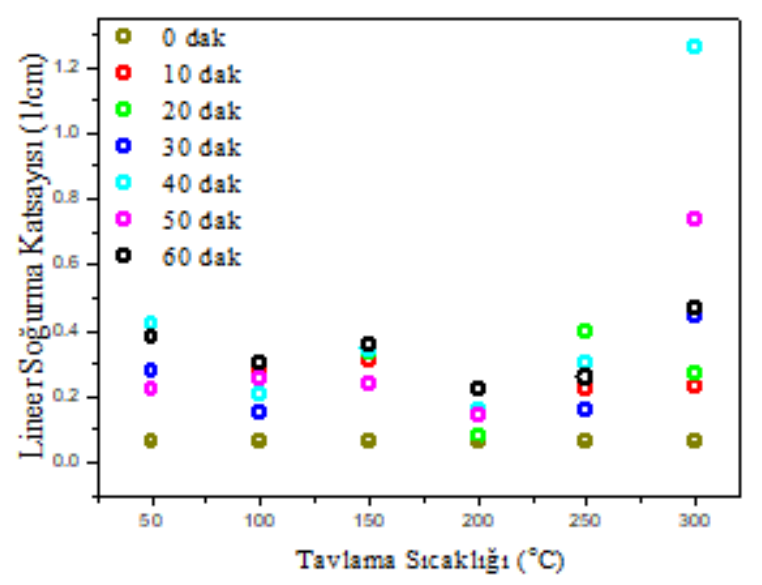

Şekil 6. InSe kristalinin farklı tavlama sürelerindeki lineer soğurma katsayılarının tavlama sıcaklığıyla değişimi 


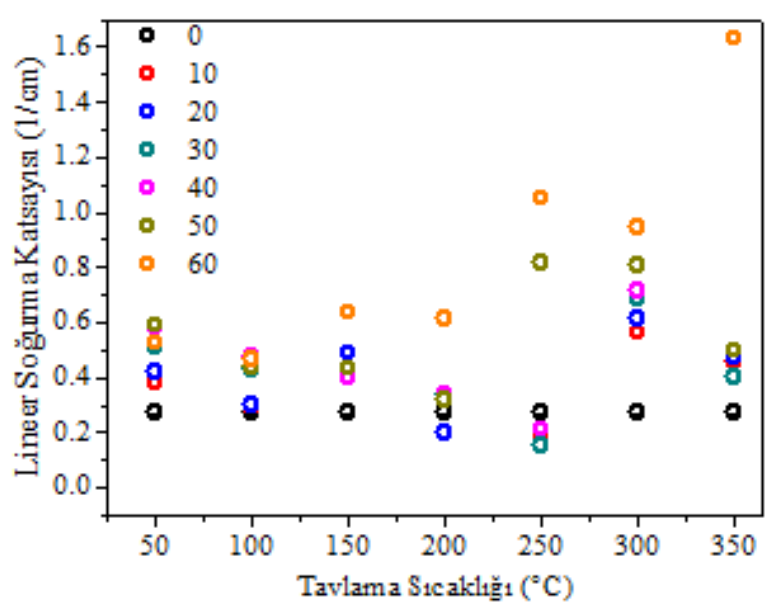

Şekil 7. InSe:Sn kristalinin farklı tavlama sürelerindeki lineer soğurma katsayılarının tavlama sıcaklığıyla değişimi

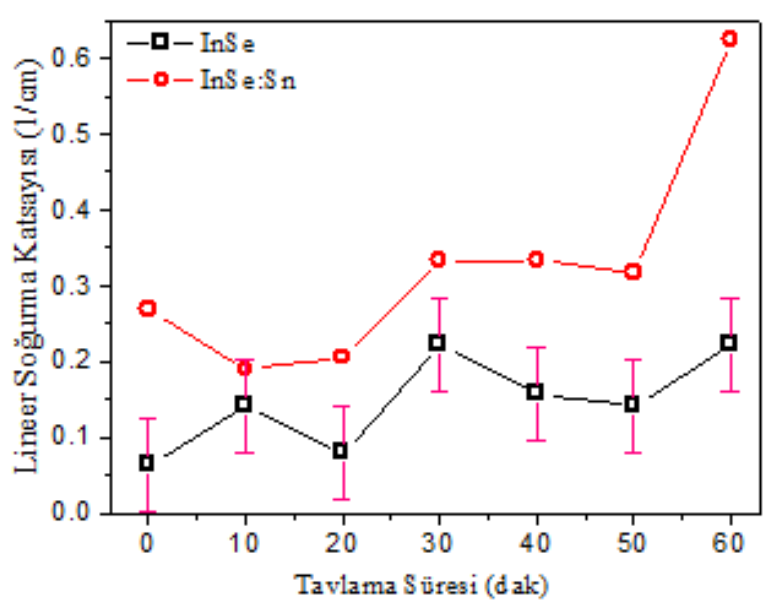

Şekil 8. InSe ve InSe:Sn kristallerinin $200{ }^{\circ} \mathrm{C}$ tavlama sıcaklığındaki lineer soğurma katsayılarının tavlama süresiyle değişimi

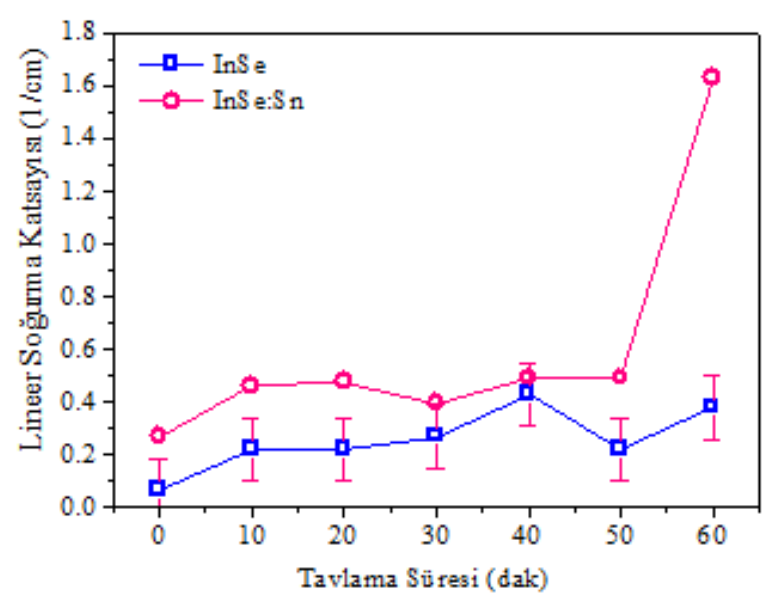

Şekil 9. InSe yariiletken kristalinin $50{ }^{\circ} \mathrm{C}$ ve InSe:Sn kristalinin $350{ }^{\circ} \mathrm{C}$ tavlama sıcaklığındaki lineer soğurma katsayılarının tavlama süresiyle değişimi

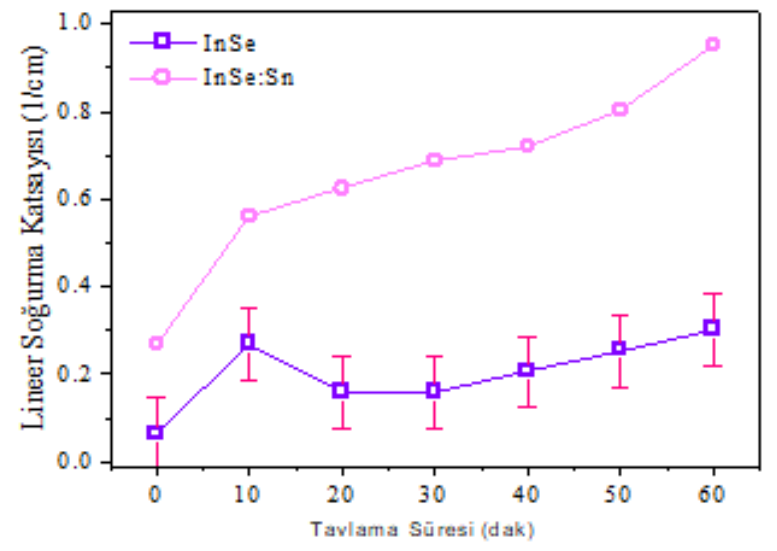

Şekil 10. InSe kristalinin $100{ }^{\circ} \mathrm{C}$ ve InSe:Sn kristalinin $300{ }^{\circ} \mathrm{C}$ tavlama sıcaklığındaki lineer soğurma katsayılarının tavlama süresiyle değişimi

\section{Sonuç}

Çalışmada elde edilen bulgular dikkate alındığında, Bridgman/Stockbarger metodu kullanılarak büyütülmüş $\mathrm{InSe}$ ve InSe:Sn yarıiletken kristallerinin uzun tavlama süresi ve yüksek tavlama sıcaklıklarına çıkıldığında genelde daha soğurucu hale geldikleri sonucuna varabiliriz. Bu durum bize, uzun tavlama süresi ve yüksek tavlama sıcaklığında yapılan tavlamanın numunenin kristal yapısında, yapısal olarak homojenliğin artmasına sebep olduğunu düşündürmektedir. InSe ve InSe:Sn kristallerinin 0-60 dakika tavlama sürelerinde bazı sıcaklıklar için benzer değișimleri SSekil 8, 9 ve 10'dan görülmektedir. Özellikle Şekil 9 incelendiğinde InSe ve InSe:Sn için 40. dakikada lineer soğurma katsay1ları hemen hemen kesişecek kadar yakın değerler almaktadır. Bu durum InSe $\left(50{ }^{\circ} \mathrm{C}\right)$ ve InSe:Sn $\left(350{ }^{\circ} \mathrm{C}\right)$ için, farklı tavlama sıcaklıkları ve aynı tavlama süresi (40 dak) için lineer soğurma katsayısının aynı değişimi veya karak-teristiği gösterdiği sonucunu ortaya çıkarmaktadır. Başka bir deyişle bu tavlama süresi ve $350{ }^{\circ} \mathrm{C}$ sicaklık için InSe:Sn, katkısız InSe gibi davranmıştır.

\section{Teșekkür}

Numuneleri hazırlayan Atatürk Üniversitesi, Fen Fakültesi, Katıhal Fiziği Bilim Dalı Öğretim Üyesi, Sayın Dr. Öğr. Üyesi Bekir GÜRBULAK'a bu değerli katkısından dolayı teşekkürlerimizi sunarız.

\section{Kaynaklar}

Abdinov, A. Sh., Babaeva, R. F., ve Rzaev, R. M., 2012. Electric Field Effect on Photoconductivity Decay in n-InSe Single Crystals. Inorganic Materials, 48 (8), 781-785. 
Akça, B., Erzeneoğlu, S. Z., ve Gürbulak, B., 2015. Measurement of $\gamma$-ray transmission factors of semiconductor crystals at various annealing temperature and time. Indian Journal of Pure \& Applied Physics, 53 (1), 49-55.

Choi, In.H., ve Peter, Y. Yu., 2003. Properties of phase-pure InSe films prepared by metalorganic chemical vapor deposition with a single-source precursor. Journal of Applied Physics, 93 (8), 4673-4677.

Darwish, A. A. A. , El-Nahass, M. M., ve Bahlol, M. N., 2013. Structural and electrical studies on nanostructured InSe thin films. Applied Surface Science, 2716, 210-216.

Erzeneoğlu, S., İçelli, O., Gürbulak, B., ve Ateş, A., 2006. Measurement of mass attenuation coefficients for holmium doped and undoped layered semiconductors InSe at different energies and the validity of mixture rule for crystals around the absorption edge. Journal of Quantitative Spectroscopy \& Radiative Transfer, 102(3), 343-347.

Imai, K., Suzuki, K., Haga, T., Haegawa, Y., Abe, Y., 1981. Phase diagram of In-Se system and crystal growth of indium monoselenide. Journal of Crystal Growth, 54, 501-506.
İçelli, O., Erzeneoğlu, S., ve Gürbulak, B., 2005. Mass Attenuation Coefficients for n-type InSe, InSe:Gd, InSe:Ho and InSe:Er Single Crystals. Journal of Quantitative Spectroscopy \& Radiative Transfer, 90 (34), 399-407.

Mooser, E., Ed., 1976. Physics and Chemistry of Material With Layered Structure, (Riedel, Dordrecht).

Neamen, D. A., 2003, Semiconductor Physics and Devices Basic Principles, Third Edition, University of New Mexico.

Olguin, D., Canterero, A., ve Syassen, U.K., 2003. Effect of Pressure on Structural roperties and Energy Band Gaps $\gamma$-InSe. Physica Status Solidi B, 235 (2), 456-463.

Pellicer-Pores, J., Segura, A., Ferrer, Ch., Munoz, V., San Miguel, A., Polian, A., Itie, J.P., Gauthier, M., ve Pascarelli, S., 2002. Highpressure X-ray-absorption study of GaSe, Physical Review B, 65(1), 174103-7.

Segura A., Guesdon, J. P., Besson, J. M., ve Chevy, A., 1983. Photoconductivity and photovoltaic effect in indium selenide. Journal of Applied Physics, 54(2), 876-889. 